\title{
Auroral electrojet dynamics during magnetic storms, connection with plasma precipitation and large-scale structure of the magnetospheric magnetic field
}

\author{
Y. I. Feldstein ${ }^{1}$, L. I. Gromova ${ }^{1}$, A. Grafe ${ }^{2}$, C.-I. Meng ${ }^{3}$, V. V. Kalegaev ${ }^{4}$, I. I. Alexeev ${ }^{4}$, Y. P. Sumaruk ${ }^{5}$ \\ ${ }^{1}$ Institute of Terrestrial Magnetism, Ionosphere and Radio Waves Propagation, Moscow Region, Russia \\ ${ }^{2}$ Geo ForschungZentrum Potsdam, Adolf Schmidt Observatorium, Niemegk, Germany \\ ${ }^{3}$ Johns Hopkins University, Applied Physics Laboratory, Laurel, MD 20723-6099, USA \\ ${ }^{4}$ Institute of Nuclear Physics, Moscow State University, Moscow, Russia \\ ${ }^{5}$ Lvov Magnetic Observatory, 292193 Lvov Region, Ukraine
}

Received: 2 February 1998 / Accepted: 11 September 1998

\begin{abstract}
Effect of the equatorward shift of the eastward and westward electrojets during magnetic storms main phase is analyzed based on the meridional chains of magnetic observatories EISCAT and IMAGE and several Russian observatories (geomagnetic longitude $\sim 110^{\circ}$, corrected geomagnetic latitudes $74^{\circ}>\Phi>51^{\circ}$.) Magnetic storms of various $D s t$ index intensity where the main phase falls on 1000 UT - 2400 UT interval were selected so that one of the observatory chains was located in the afternoon - near midnight sector of MLT. The eastward electrojet center shifts equatorward with $D s t$ intensity increase: when $D s t \sim-50 \mathrm{nT}$ the electrojet center is located at $\Phi \sim 62^{\circ}$, when $D s t \sim-300 \mathrm{nT}$ it is placed at $\Phi \sim 54^{\circ}$. The westward electrojet center during magnetic storms main phase for intervals between substorms shifts equatorward with $D s t$ increase: at $\Phi \sim 62^{\circ}$ when $D s t \sim-100 \mathrm{nT}$ and at $\Phi \sim 55^{\circ}$ when Dst $\sim-300 \mathrm{nT}$. During substorms within the magnetic storms intervals the westward electrojet widens poleward covering latitudes $\Phi \sim 64^{\circ}-65^{\circ}$. DMSP (F08, F10 and F11) satellite observations of auroral energy plasma precipitations at upper atmosphere altitudes were used to determine precipitation region structure and location of boundaries of various plasma domains during magnetic storms on May 10-11, 1992, February 5-7 and February 21-22, 1994. Interrelationships between center location, poleward and equatorward boundaries of electrojets and characteristic plasma regions are discussed. The electrojet center, poleward and equatorward boundaries along the magnetic observatories meridional chain were mapped to the magnetosphere using the geomagnetic field paraboloid model. The location of auroral energy oxygen ion regions in the night and evening magnetosphere is determined. Considerations are presented on the mechanism causing the appearance in the inner magnetosphere during active intervals of magnetic storms of ions with energy of tens $\mathrm{KeV}$. In the framework of the magnetospheric magnetic
\end{abstract}

Correspondence to: Y. I. Feldstein field paraboloid model the influence of the ring current and magnetospheric tail plasma sheet currents on largescale magnetosphere structure is considered.

Key words. Ionosphere (particle precipitation), Magnetospheric physics (current systems; magnetospheric configuration and dynamics).

\section{Introduction}

Geophysical phenomena accompanying appearance of magnetic storms are observed well equatorward of auroral latitudes $65^{\circ}<\Phi<67^{\circ}$ (Akasofu and Chapman, 1972; Khorosheva, 1987). Informed opinion varies about auroral electrojet locations, the intense ionospheric currents with magnitudes of up to $10^{6} \mathrm{~A}$ routinely observed at auroral latitudes $\Phi \sim 65^{\circ}$. Weimer et al. (1990) believes, that the auroral electrojets remain at $\Phi>60^{\circ}$ during magnetic storms accompanied by intensive ring current generation. Khorosheva (1986) and Feldstein et al. $(1994,1997)$ using data from several magnetic storms showed an auroral electrojet shift to subauroral latitudes during magnetic storm main phases. Khorosheva (1986) used observations of magnetic station networks and relied on data from literature, Feldstein et al. $(1994,1997)$ processed measurements of the longitudinal chain of subauroral magnetic observatories or latitudinal EISCAT magnetometers chain.

A detailed picture of dynamics of the equatorward boundaries of plasma precipitations during the intense magnetic storm on February 7-9, 1986 was presented by Swider (1990). Use was made of measurements of electron and ion fluxes with energy ranges from $30 \mathrm{eV}$ to $30 \mathrm{keV}$ aboard DMSP F06 and F07 satellites. Distinct equatorward shift of the equatormost MLAT values of the boundaries for precipitating ions and electrons was recorded for both Northern and Southern Hemispheres. 
For particles with energy between $1 \mathrm{keV}$ and $30 \mathrm{keV}$ in the night sector this shift varies from $\Phi \sim 65^{\circ}$ for $D s t=-10 \mathrm{nT}$ to $\Phi \sim 50^{\circ}$ for $D s t=-300 \mathrm{nT}$. Kuznetsov (1996) observed a similar dependence for low latitude boundary of the ion precipitation based on Intercosmos-17 data.

Below we continue to document electrojet positions and investigation of electrojet dynamics based on meridional magnetic observatory chains data, EISCAT and IMAGE (Luehr et al., 1984; Viljanen and Hakkinen, 1996) observations. We also use measurements of middle latitudinal and subauroral Russian magnetic observatories near $110^{\circ}$ geomagnetic meridian as well.

Special attention was paid to investigation of the relationship between electrojet location structures and spectral features of auroral plasma precipitating particles. Dronov et al. (1988) on the basis of Kosmos-900 satellite measurements showed that the ring current region, characterized by precipitation of protons with $50 \mathrm{keV}<E_{p}<80 \mathrm{keV}$ energy, experiences quasiperiodic widening and shrinking. Simultaneously the equatorward (poleward) boundaries shift to low (high) latitudes. The eastward electrojet is located near the ring current main peak, while high latitudinal maxima of electron and proton precipitations lie within the westward electrojet region.

Meridional magnetic observatories chain data allow us to more precisely determine the auroral electrojet boundaries location, while DMSP satellite spectrograms with $1 s$ temporal resolution for electrons and ions of energy between $10 \mathrm{eV}$ and $20 \mathrm{keV}$ make possible stateof-the-art identification of plasma precipitation regions with various spectral and structural characteristics (Sanchez et al. 1993). Mapping of electrojet boundaries from ionospheric altitude to the magnetosphere reveals locations of plasma structures, connected with the electrojets by magnetic field lines. The paraboloid magnetospheric magnetic field model (Alexeev et al., 1996 ) is used for the mapping. This model allows more detail, compared with other models, to describe the magnetospheric magnetic field dynamics in their dependence on several physically important magnetospheric parameters. In the framework of this model the influence of the model input parameters on the location of characteristic magnetic field lines in the magnetosphere is considered.

\section{Auroral electrojet dynamics in the intervals of magnetic storms}

Fig. 1 presents variations of the northern $(X)$ component of the geomagnetic field along the IMAGE chain during the magnetic storm on February 5-7, 1994 (top). The variation intensity was measured relative to the level at 0600-0800 UT on February 5, 1994. Dotted vertical lines correspond to UTs with latitudinal cross sections of $X$ and $Z$ geomagnetic field components during maxima of eastward and westward electrojets and quiet intervals between substorms. The location of the MLT midnight in each station is marked by triangle. Usually IMAGE chain intersects the eastward electrojet in early evening hours and the westward electrojet near midnight and in early morning hours. During magnetic storms the eastward electrojet is recorded by IMAGE at near noon hours. Dst and $P C$ variations of the geomagnetic field for the same storm is shown at the bottom. Arrows directed downwards (upward) mark moments of latitudinal cross sections through eastward (westward) electrojets.

The magnetic storm had begun with $D s t$ variation decrease after 1100-1200 UT on February 5, 1994. Dst variation reached $-80 \mathrm{nT}$ at $2000-2100 \mathrm{UT}$ and then became weaker. The magnetic storm maximum falls on 1600-2200 UT on February 6 (Dst $\sim-120 \mathrm{nT}$ ), on February 7 Dst variation decays (the recovery phase). The storm decay in Dst index occurs irregularly. Stormtime increases of $|D s t|$ are connected with substorm manifestations. $K_{p}$ indices, which characterize the magnetic disturbance level at middle latitudes, in general repeat Dst variation: at $0900-1200$ UT on February 5 disturbance increases up to $K_{p}=5_{0}$, at 2100-2400 UT $K_{p}$ had $6_{-}$value, while maximum $K_{p}=6_{0}-6_{+}$took place at 1500-2400 UT on February $6 . K_{p}$ does not decrease monotonously on February 7 , increases are superceded by decreases. This is the effect of magnetospheric substorms, occurring at the magnetospheric storm recovery phase.

Unfortunately $A E$ indices, characterizing the auroral electrojets planetary intensity, are unavailable for us during this concrete storm. However, the $P C$ index of the magnetic activity developed by Troshichev et al. (1979), Vennerstrom et al. (1991) to describe the disturbance level at the polar cap center region due to $B_{z}$ IMF component gives an indication on the level of disturbances in high-latitude regions. $P C$ was determined for every 15-min interval allowing for horizontal components of magnetic disturbance vector deviations from the quiet level and the speed of this vector changes. For the interval under consideration the index was calculated based on Thule station observations, near the geomagnetic pole in Greenland. A close connection between $P C$ intensity increase and $D s t$ is clearly seen (Fig. 1): increase of $P C$ from 0 to 4 points at 1200 UT on February 5, remaining at this level till $\sim 2300$ UT with a consequent decrease to $\sim 1$ point at $0600-0700$ UT on February 6. New sharp activity intensification up to 11 points at 1600 UT (the storm main phase) and reduction to 1 point at 0200 UT on February 7 was measured.

At the recovery phase of magnetic storm on February 7, 1994 intensifications of $P C$ index at 0400 UT, 1500 UT and 1900 UT were recorded.

Latitudinal cross sections $\Delta X$ and $\Delta Z$ when magnetometer chain recorded the eastward electrojet for magnetic storm February 5-7, 1994 are presented Fig. 2. The electrojet centers are marked by arrows. Their location is determined by maximum $\Delta X$ value and change of sign of $\Delta Z(\Delta Z<0$ poleward of the electrojet center latitude and $\Delta Z>0$ equatorward of it). Usually the eastward electrojet center is located at $\Phi \sim 65^{\circ}$ 


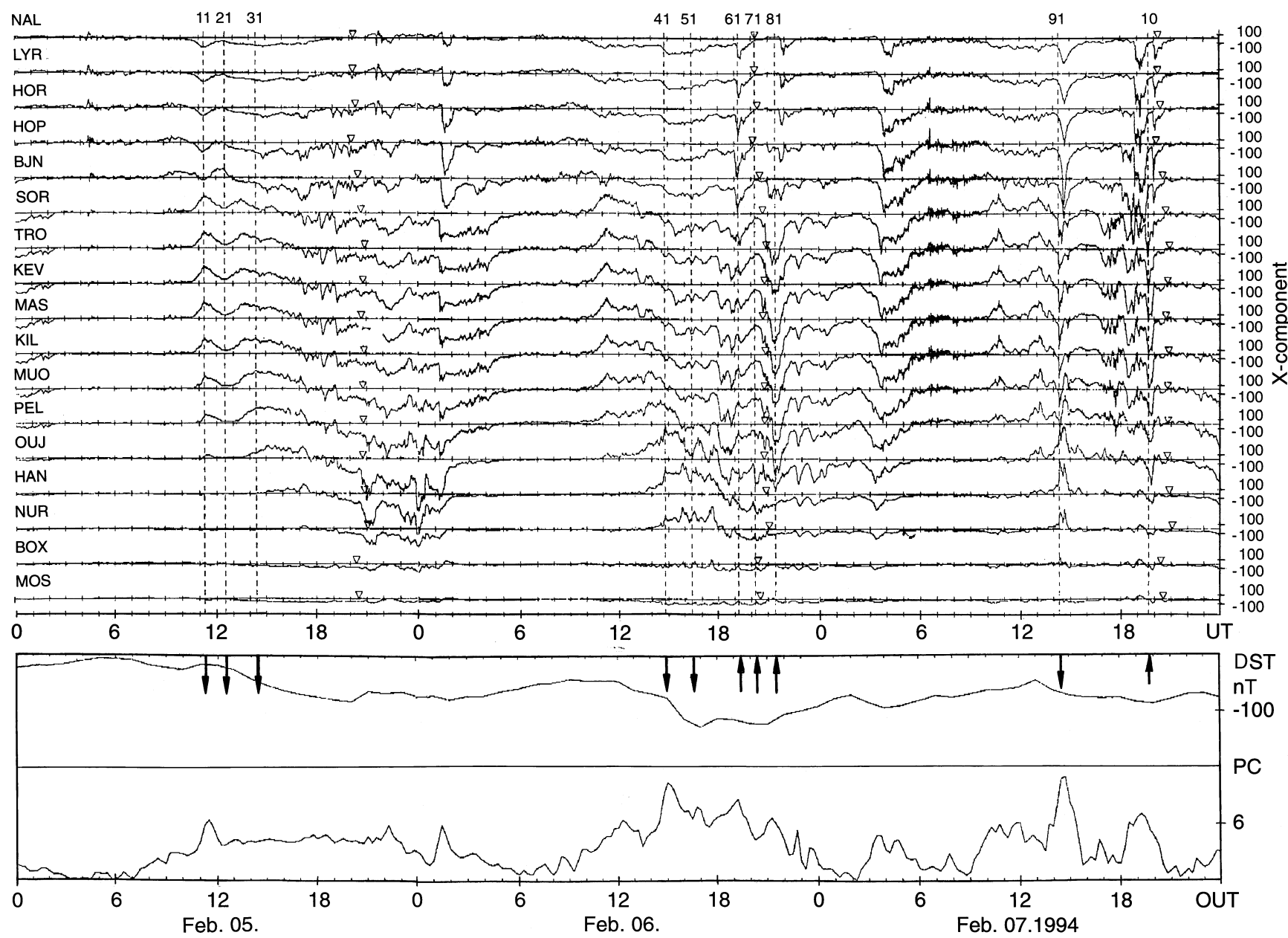

Fig. 1. Variations of the magnetic field $X$ component along the IMAGE chain during storm main phase on February 05-07, 1994(top). Dotted lines (vertical) correspond to 10 UTs with latitudinal cross sections of the $\Delta X$ and $\Delta Z$ components presented further in the text. The Dst and the $P C$ indices of the magnetic field

variations for the same storm are shown at the bottom. Arrows directed downwards mark UTs of latitudinal cross section through the eastward electrojet, and arrows directed upwards mark cross sections through the westward electrojet. The location of the magnetic midnight in each station is marked by a triangle

during substorms, but in the intervals between substorms at somewhat higher latitudes (Kamide and Akasofu, 1974). This peculiar feature of the eastward electrojet location is demonstrated in Fig. 2 by latitudinal cross sections. Prior to the magnetic storm on February 5 onset the eastward electrojet centers are located at $\Phi=66.5^{\circ}$ at 11.18 UT (during substorm maximum) and at $\Phi=69.5^{\circ}$ at $12.31 \mathrm{UT}$ (in the interval between adjacent substorms). Immediately after the magnetic storm commencement the electrojet center was located at $\Phi=64.3^{\circ}$ at 14.24 UT during substorm maximum $(D s t=-42 \mathrm{nT})$. When $D s t$ increases to -68 $\mathrm{nT}$, in approximately similar conditions of substorm maximum and the same MLT, the eastward electrojet center is located ar $\Phi=61^{\circ}$ at 14.48 UT on February 6 . The eastward electrojet shift equatorwards continues with $|D s t|$ increase till $\Phi=58.5^{\circ}$ at 16.28 UT for $D s t=-114 \mathrm{nT}$. At the magnetic storm recovery phase the eastward electrojet center following Dst variation mitigation shifts to higher latitudes, up to $\Phi=60^{\circ}$ at 14.21 UT on February 7, 1994. Summing up dynamics of the eastward electrojet in the course of the magnetic

storm on February 5-7, 1994, we came to the conclusion that the eastward electrojet center during substorms maximum is located consequently at $\sim 17-18$ MLT at the following corrected geomagnetic latitudes: $66^{\circ} ; 64^{\circ}$; $61^{\circ} ; 58.5^{\circ} ; 60^{\circ}$ with $D s t$ values $-14 \mathrm{nT} ;-42 \mathrm{nT} ;-68 \mathrm{nT}$; $-114 \mathrm{nT} ;-63 \mathrm{nT}$, correspondingly.

A dashed line in Fig. 2e marks the location of the eastward electrojet center during an intensive magnetic storm on May 10, 1992 main phase, which is analyzed in detail by Feldstein et al. (1997). At 15.14 UT, when $D s t=-282 \mathrm{nT}$, the electrojet center shifted to $\Phi=55.0^{\circ}$. Hence, really the value of equatorward shift is conditioned by the $D s t$ variation enhancement. The corresponding dependence of the eastward electrojet center location on Dst is presented in Fig. 3.

Latitudinal cross sections in Fig. 2 clearly demonstrate the existence of westward current poleward of the eastward electrojet. This westward current is located along the auroral oval evening sector (Akasofu, 1968), and the boundary between the eastward and westward electrojets in the evening sector was called the Harang discontinuity. The discontinuity latitude changes not 

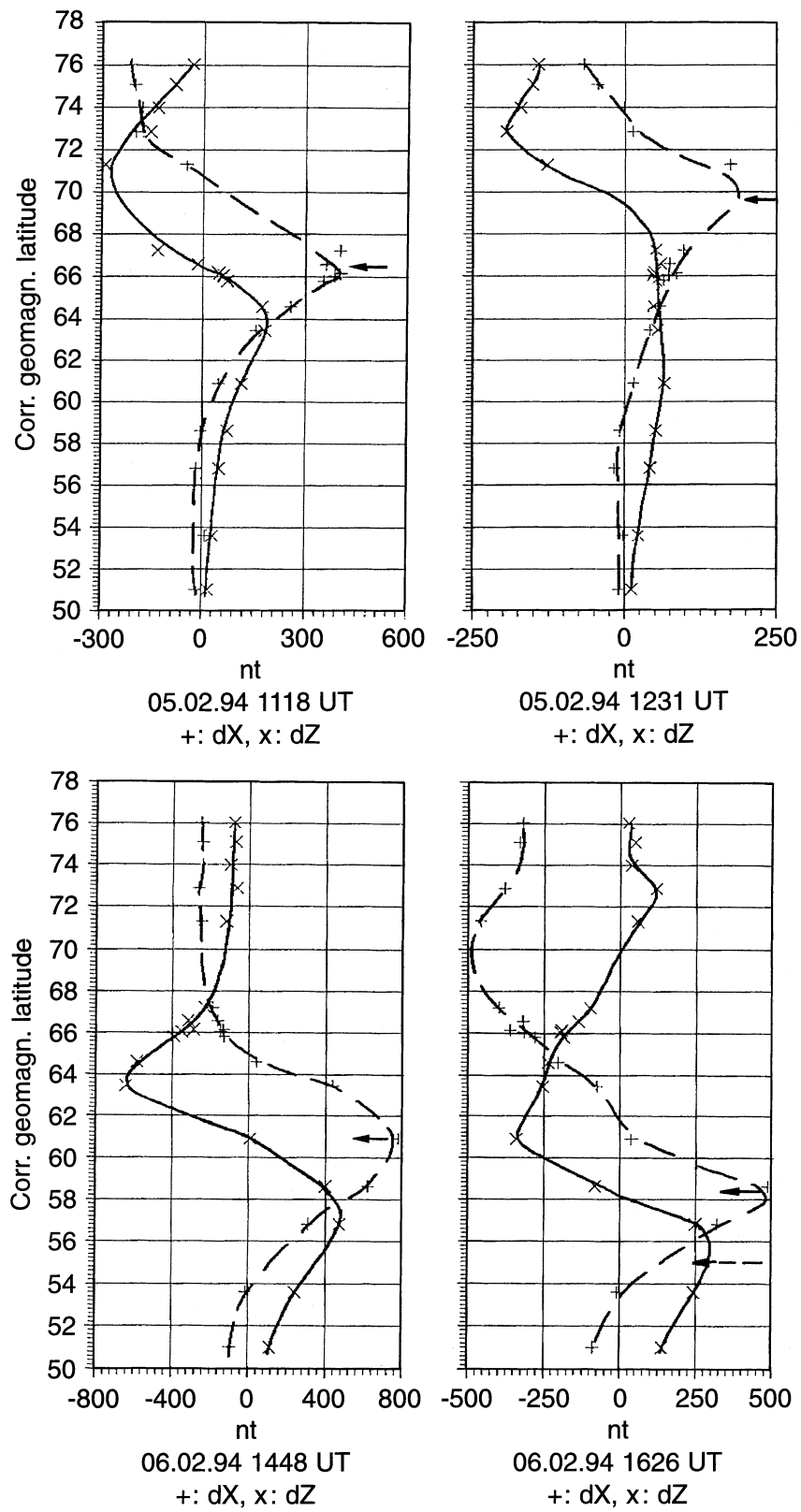

05.02.94 1231 UT

$+: d X, x: d Z$

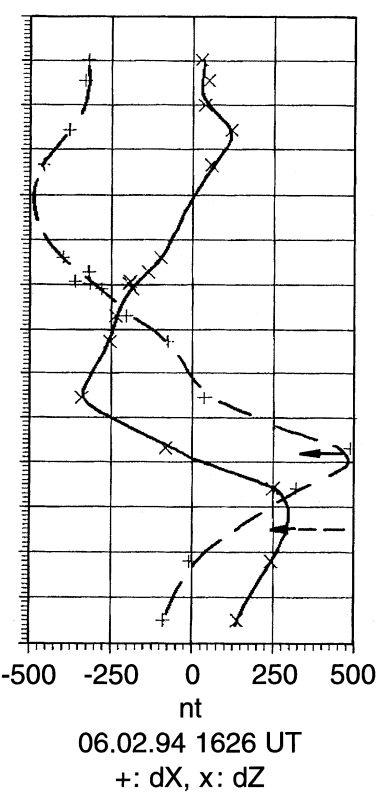

$+: d X, x: d Z$

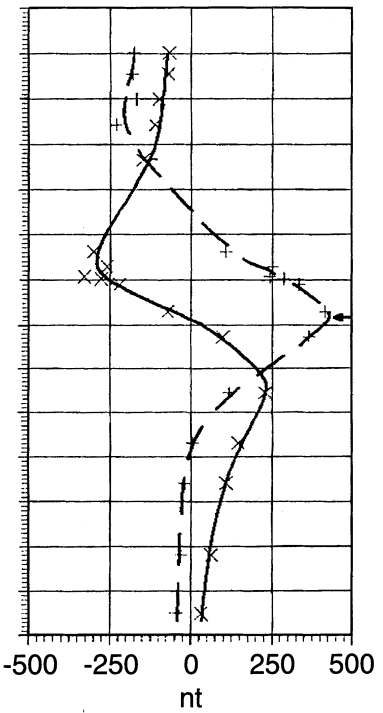

05.02.94 1424 UT $+: \mathrm{dX}, \mathrm{x}: \mathrm{dZ}$

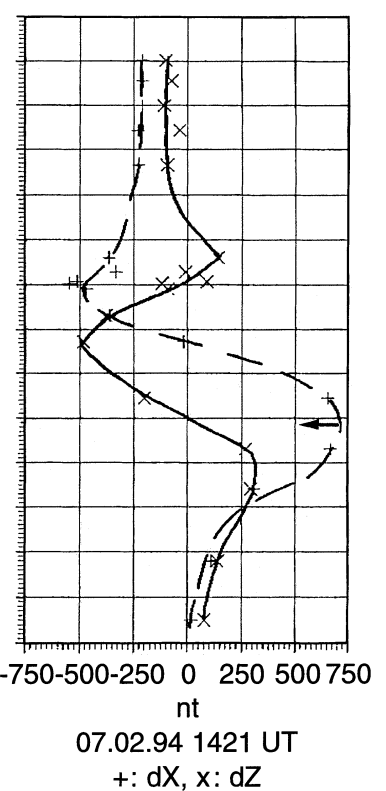

Fig. 2a-f. The latitudinal cross sections $\Delta X$ (dashed line) and $\Delta Z$ (solid line) through the eastward electrojet on February 05, 1994 at 1118 UT, 1231 UT and 1424 UT, February 06 at 1448 UT and 1628 UT, February 07 at 1421 UT. Arrows mark the latitudes of the eastward electrojet center. The dashed arrow on February 06 at 1626 UT marks the position of the eastward electrojet on May 10, 1992 at 1514 UT, when $D s t=-282$ nT only in connection with the local geomagnetic time similar to the auroral oval, but it depends on Dst intensity as well. Fig. 3 shows this dependence for the magnetic storm on February 5-7, 1994. The discontinuity is naturally located at higher latitudes than the eastward electrojet center and it shifts discernibly equatorwards as $D s t$ variation increases.

The character of latitudinal cross sections through the westward, presented in Fig. 4, and the eastward electrojets is substantially different (Grafe et al. 1987). The westward current at near midnight and early morning hours MLT covers practically the whole auroral zone in the latitudinal interval $60^{\circ}<\Phi<75^{\circ}$. During relatively quiet intervals between substorms, such as the precise time of 20.14 UT on February 6, the electrojet center was located at $\Phi \sim 60^{\circ}$. It is about $5^{\circ}$ equatorward of the usual location of the westward electrojet in the near midnight sector. At the substorm maximums, of 19.14 UT and 21.26 UT on February 6, 19.40 UT on February 7, 1994 the electrojet center does not shift equatorward but the electrojet sharply widens poleward. An electrojet latitudinal splitting with more than one peak in $\Delta X$ is often observed. Fig. 4 contains such an example at 19.14 UT. In addition to main maximum of intensity at $\Phi \sim 71^{\circ}$, the latitudinal cross section contains one additional weaker maximum at $\Phi \sim 61^{\circ}$. Consideration of the westward auroral electrojet dynamics for quiet intervals between substorms showed reasonable agreement with statistical data comprising other magnetic storms presented by Feldstein et al. (1997). It is very peculiar that for both the eastward and westward electrojets their shift equatorward in the course of a magnetic storm development begins from auroral zone latitudes $\left(65^{\circ}<\Phi<67^{\circ}\right)$ and ends at $\Phi \sim 55^{\circ}$ with $D s t \sim-250 \mathrm{nT}$. 


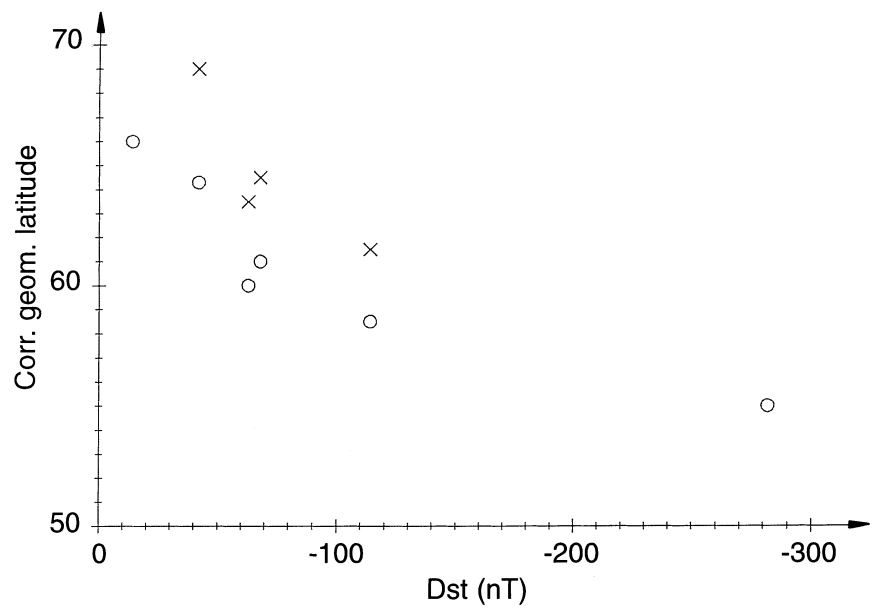

Fig. 3. The position of the eastward electrojet center (circles) and Harang discontinuity (crosses) at 17-18 MLT during magnetic storms on February 05-07, 1994 and May 10, 1992

\section{Auroral electrojet and precipitating charged particles of auroral energy}

It has long been known that auroral electrojets are located in the region of the most frequent appearance of aurorae produced by precipitating plasma particles with energy between $10 \mathrm{eV}$ and $10^{4} \mathrm{eV}$. As a rule, eastward electrojets are observed in the evening (MLT ) hours and westward ones along the auroral oval with the highest intensity at near midnight and early morning hours of MLT. Structure of the auroral precipitation region in the auroral oval night sector was discussed in detail by Feldstein and Galperin (1985). Boundaries of various structural regions below are fixed in accordance with the Newell et al. (1996), and Feldstein and Galperin (1996) classification. This classification is based on physically substantiated boundaries of regions with different physical characteristics as far as structure of precipitating plasma fluxes and their energy spectra ranging from a few $\mathrm{eV}$ to several thousands $\mathrm{eV}$ are concerned (Galperin and Feldstein, 1991, 1996). The new system of identification uses only spectrograms from lowaltitude satellites. Algorithms for identification of boundaries by a computer without intervention of a researcher are developed in Newell et al. (1996).

On the basis of physical characteristics of electron and ion fluxes above the ionosphere definite relationship between these plasma structures and plasma domains in the magnetospheric tail (Galperin and Feldstein 1996) is offered. Newell et al. (1996) proposed the following indentification of the plasma regions in the auroral oval night sector. Boundary ble is the "zero-energy" electron boundary, usually determined by the 32 and $47 \mathrm{eV}$ electron channels; boundary b2i is precipitating ion energy flux maximum, which is also the isotropy boundary for ions and the current sheet inner boundary in the plasma sheet of the magnetospheric tail; boundary b2e is the point where electron average energy is neither increasing nor decreasing with latitude: one interpretation is the start of the main (central) plasma sheet
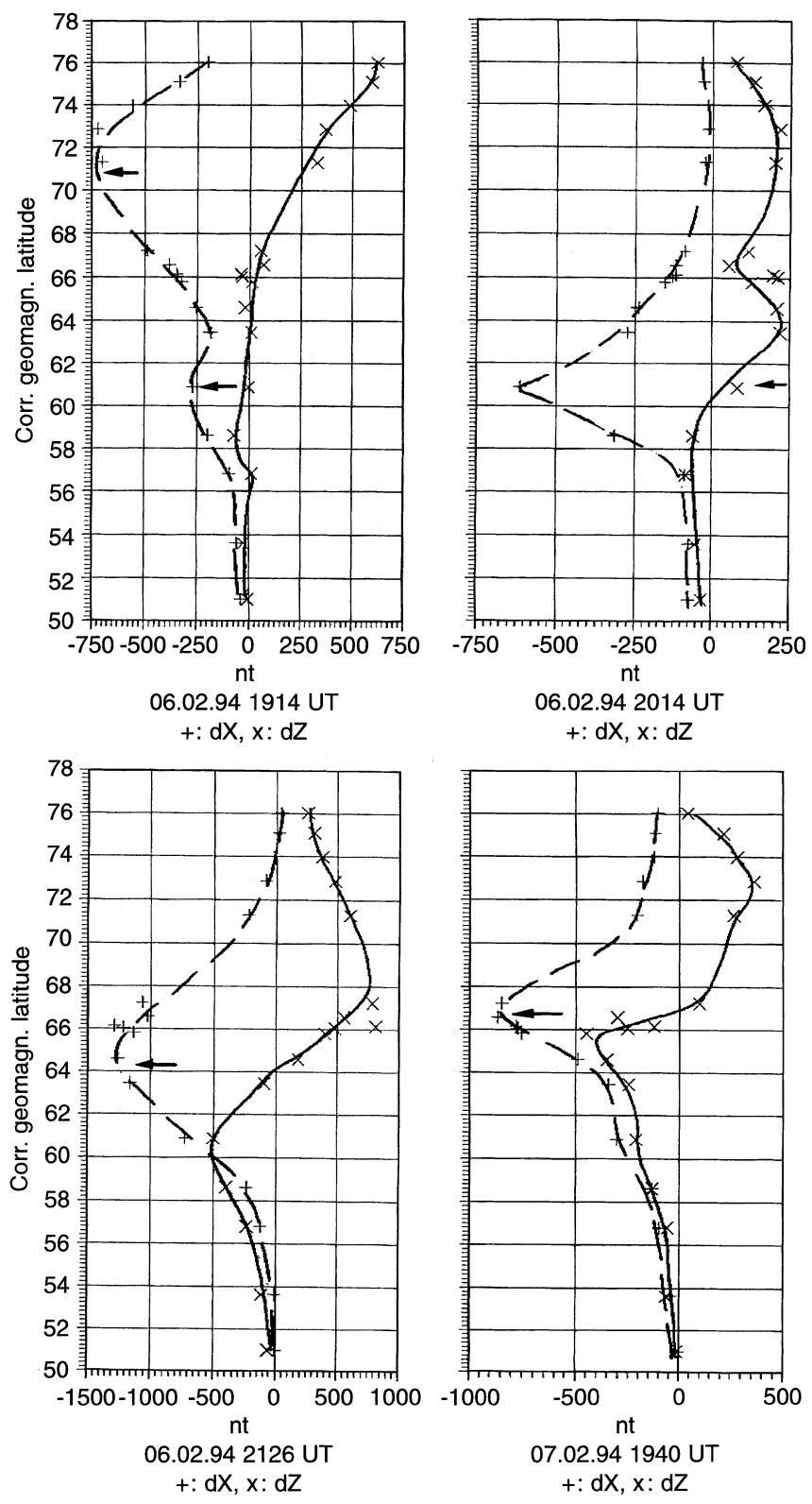

Fig. 4. The latitudinal cross sections through the westward electrojet on February 06, 1994 at 1914 UT and 2126 UT, February 07 at 1940 UT during substorms maxima, on February 06, 1994 at 2014 UT during quiet intervals between substorms. Arrows mark the latitudes of the westward electrojet center

precipitation; boundary $\mathrm{b} 3 \mathrm{a}$ is the equatorwardmost electron acceleration event identified, equatorial boundary of the structural auroral forms (equatorial auroral oval boundary); boundary b3b is the polewardmost such event, polar boundary of the discrete auroral forms (auroral oval polar boundary); boundary b6 is the poleward boundary of subvisual drizzle roughly adjacent to the auroral oval. At near midnight hours boundaries b2e and b3a very often are practically identical but diverge to several degrees along latitude in evening and morning hours.

Fig. 5 shows boundaries for the eastward electrojet using evidence of magnetometer chains and location of 


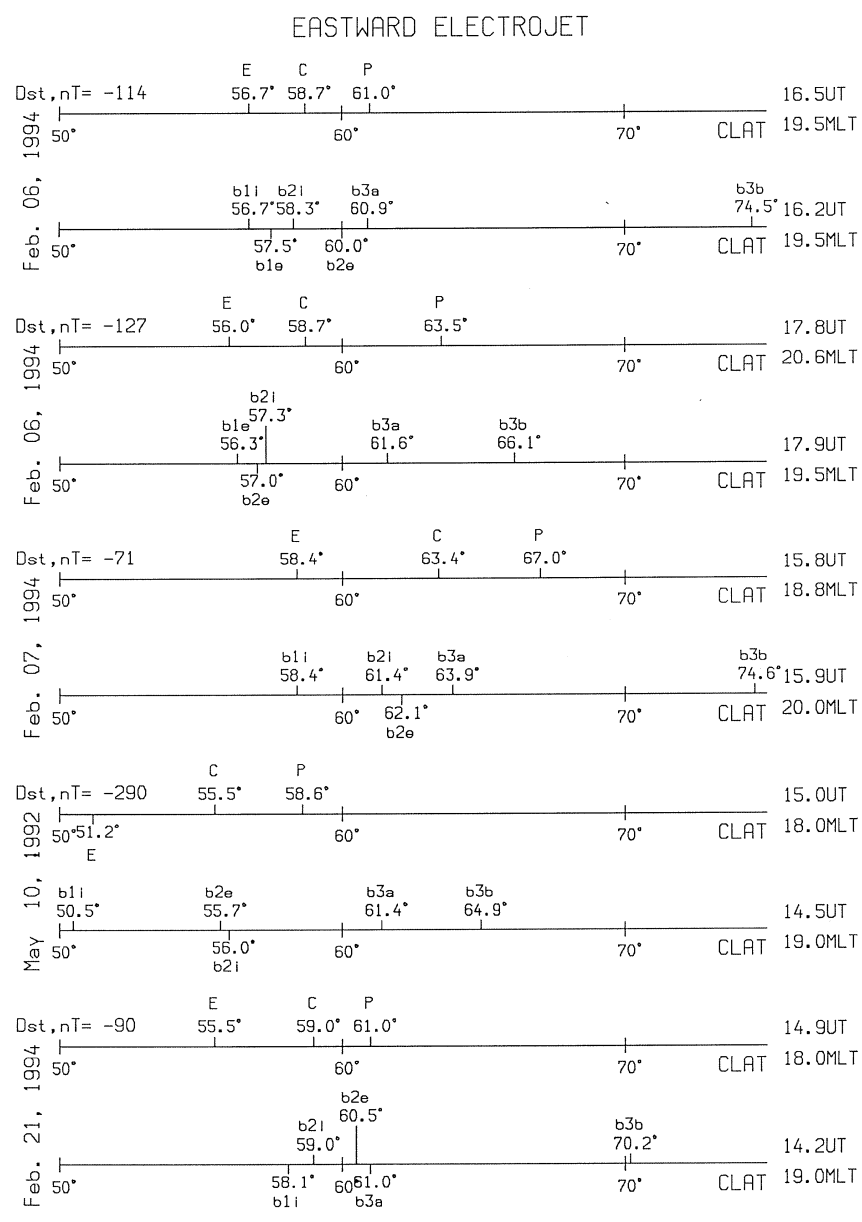

Fig. 5. The center $(C)$ and boundaries ( $E$, equatorial and $P$, polar) of eastward electrojets in the course of magnetic storms on February 06 07, February 21, 1994 and May 10, 1992 in the evening sector. For DMSP F08 and DMSP F10 passes with UT and MLT crossing close to electrojets the location of plasma domain boundaries according to Newell et al. (1996) is presented: ble, $i$, are boundaries of "zero energy", usually determined by the softness channels; $b 2 e$ are points where electron average energy is neither increasing nor decreasing with latitude; $b 2 i$ is precipitating ion energy flux maximum; $b 3 a$ is the most equatorward electron acceleration event identified, equatorial boundary of the structural auroral forms; $b 3 b$ is the most poleward such event, polar boundary of the discrete auroral forms. Hourly mean $D s t$ values correspond to UT of passes

plasma domains boundaries based on DMSP F08 and F10 satellite data during magnetic storms on February 6-7, 1994, May 10, 1992 and February 21, 1994. Satellites intersected the auroral region within $0.1-0.5$ UT interval from time of electrojet locations determination. Poleward and equatorward boundaries of electrojets were defined on either side on an electrojet center as latitudes where $\Delta Z$ reached extreme values and $\Delta X \sim \Delta X \max / 2$.

The eastward electrojet in the evening sector is located either completely equatorward of the discrete auroral forms region ( $\Phi_{p}<\Phi_{b 3 a}$ ), or its poleward boundary is placed between discrete precipitation region boundaries $\left(\Phi_{b 3 a}<\Phi_{p}<\Phi_{b 3 b}\right)$. The electrojet center falls either on b2i boundary latitude (or near this latitude), the equatorward boundary practically coincides with the equa- torward boundary of plasma precipitation b1e, which apparently is the projection of the plasmapause to the ionospheric altitudes. Thus, the eastward electrojet is located mainly in the region of diffuse auroral luminosity (equatorward of b3a). However, the eastward electrojet poleward part, in separate cases, can cover the region of discrete precipitation between boundaries $b 3 a$ and $b 3 b$ as well. The eastward electrojet poleward boundary, as a rule, is located equatorward of b3b, i.e., structured auroral precipitation encompasses the region poleward of the eastward electrojet. Thus eastward electrojet is located mainly equatorward of auroral discret forms region namely equatorward of auroral oval. The eastward electrojet currents do not flow in the auroral oval as Rostoker et al. (1997) have proposed. The eastward electrojet is mapped by the geomagnetic field lines into the magnetosphere to the ring current region which is located in the inner magnetosphere earthward of the plasma sheet to which the auroral oval is mapped.

Thus in the wide interval of Dst intensity changes, in the first approximation, it can be assumed that the eastward electrojet equatorial boundary coincides with the plasmapause projection to ionospheric heights and the electrojet center coincides with latitude of ions precipitating to the upper atmosphere energy flux maximum. The latitude of this maximum lies equatorward of the ionospheric projection of the magnetospheric tail plasma sheet inner boundary. All these give reason to believe that the eastward electrojet in the evening sector of the magnetosphere is connected with processes in the inner magnetospheric regions adjacent to the plasma sheet inner boundary.

DMSP F08 orbits are oriented relative to sunward direction and for the storm on February 5-7, 1994 intersect the auroral region with the westward electrojet at $\sim 0500$ MLT. Fig. 6 presents the westward electrojet center, equatorward and poleward boundaries for IMAGE meridian at the moment of the satellite's intersection of the auroral region morning sector. The electrojets are entirely located in the latitudinal range of auroral plasma precipitations covering both diffuse and discrete precipitations. In this case precipitations extend to lower latitudes than the electrojet equatorward boundary. The electrojet center coincides with or lies in the vicinity of the auroral discrete forms equatorial boundary (b3a). The electrojet poleward boundary generally coincides with the poleward boundary of the auroral discrete forms (b3b).

In the intervals of very intense magnetic storms the westward current in the late evening hours covers the whole auroral region. For the storm on May 10, 1992 the DMSP F08 satellite intersected the evening sector at 18.01 UT, i.e., near the moment of the substorm development maximum at 18.06 UT and for Dst $=-200 \mathrm{nT}$. Fig. 6 shows the locations of plasma boundaries for this pass. Practically the whole electrojet, including its equatorward and poleward boundaries, is located at discrete auroral forms latitudes in the evening sector.

The westward electrojet is a characteristic feature of the nearmidnight sector. Fig. 7 shows such meridional 
WESTWARD ELECTROJET
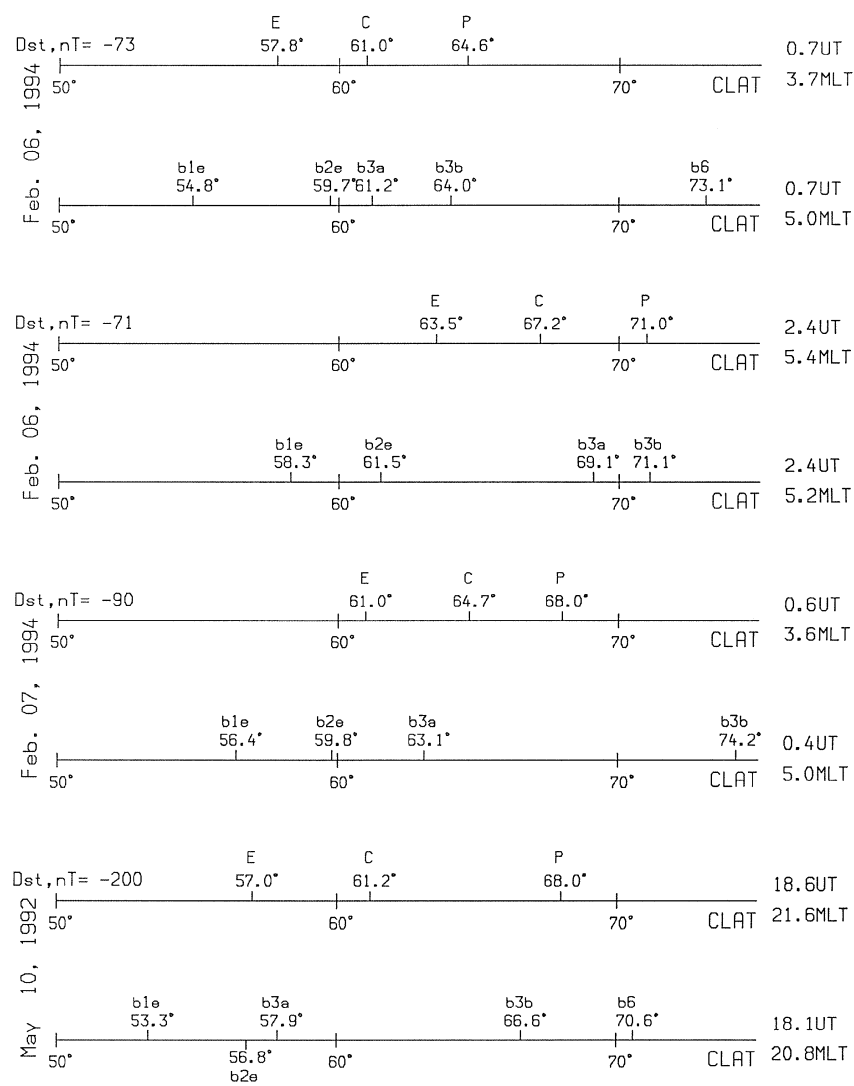

Fig. 6. Similar to Fig. 5 for westward electrojets during magnetic storms on February 06-07, 1994 and May 10, 1992 in the morning sector. In addition to plasma domain boundaries $b 1-b 3$ the position of $b 6$ boundary is shown; $b 6$ is the poleward boundary of subvisual drizzle

cross sections through the electrojets when simultaneous data on plasma structures boundaries location in evening and morning sectors of MLT are available. Cross sections on February 5, 1994 fall on the magnetic field perturbations decay after disturbances, cross sections on February 6, 1994 coincide with the substorm maximum development.

The electrojet centers and both latitudinal boundaries at quiet intervals are shifted toward lower latitudes relative to substorm intervals. And it occurs in spite of Dst increasing from $\sim-60 \mathrm{nT}$ to $\sim-(100-120) \mathrm{nT}$ in the course of the disturbance. The electrojets at midnight sector are located in the same latitudinal intervals as both diffuse and discrete precipitations in the morning and evening hours. The electrojet equatorward boundary $(E)$ in quiet intervals corresponds to ble, i.e., latitude of appearance of auroral electron precipitations, and in disturbed intervals ble is located at $\sim 4^{\circ}$ equatorward of $E$. The electrojet center in quiet intervals corresponds to the latitude, which separates diffuse and discrete precipitation regions. In disturbed intervals the electrojet center shifts to the discrete precipitation region latitudes. Auroral precipitations cover, as a rule, latitudes poleward of the electrojet poleward boundary.

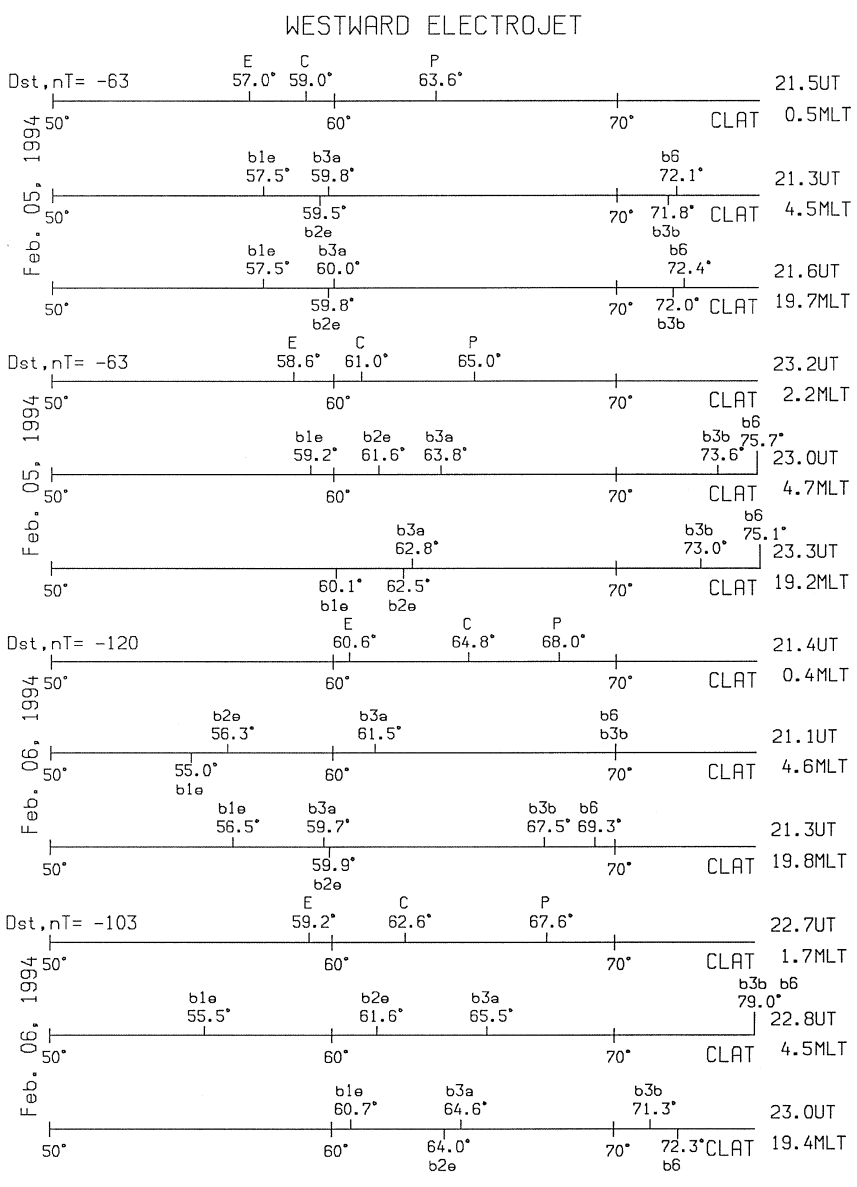

Fig. 7. Similar to Fig. 5 for westward electrojets on February $05-06$, 1994 at near midnight MLT hours and location of plasma domain boundaries at the evening and morning hours MLT

\section{Electrojets mapping to magnetosphere}

Latitudinal intervals where electrojets are located were mapped to the magnetosphere. The paraboloid model of the magnetic field in the magnetosphere (Alexeev et al., 1996) was used for mapping. Input parameters of this model are the physically accurate magnetospheric characteristics and therefore it has definite advantages in comparison with widely known Tsyganenko's model (Tsyganenko, 1987, 1989). Tsyganenko's model belongs to empirical models, while Alexeev's model is a conceptual one.

The input parameters in the paraboloid model are the following magnetospheric characteristics:

1. The geomagnetic dipole axis orientation (angle $\psi$ );

2. The magnetic field flux in tail lobes $\left(\Phi_{\infty}\right)$;

3 . The ring current magnetic field intensity $\left(B_{R C}\right)$;

4. Geocentric distances to subsolar magnetopause point $\left(R_{1}\right)$, to the earthward boundary of the tail current $\left(R_{2}\right)$.

These characteristics may be determined from observational data on the solar wind parameters, boundaries of auroral precipitation regions. For determination of the midnight and noon auroral oval boundaries based 


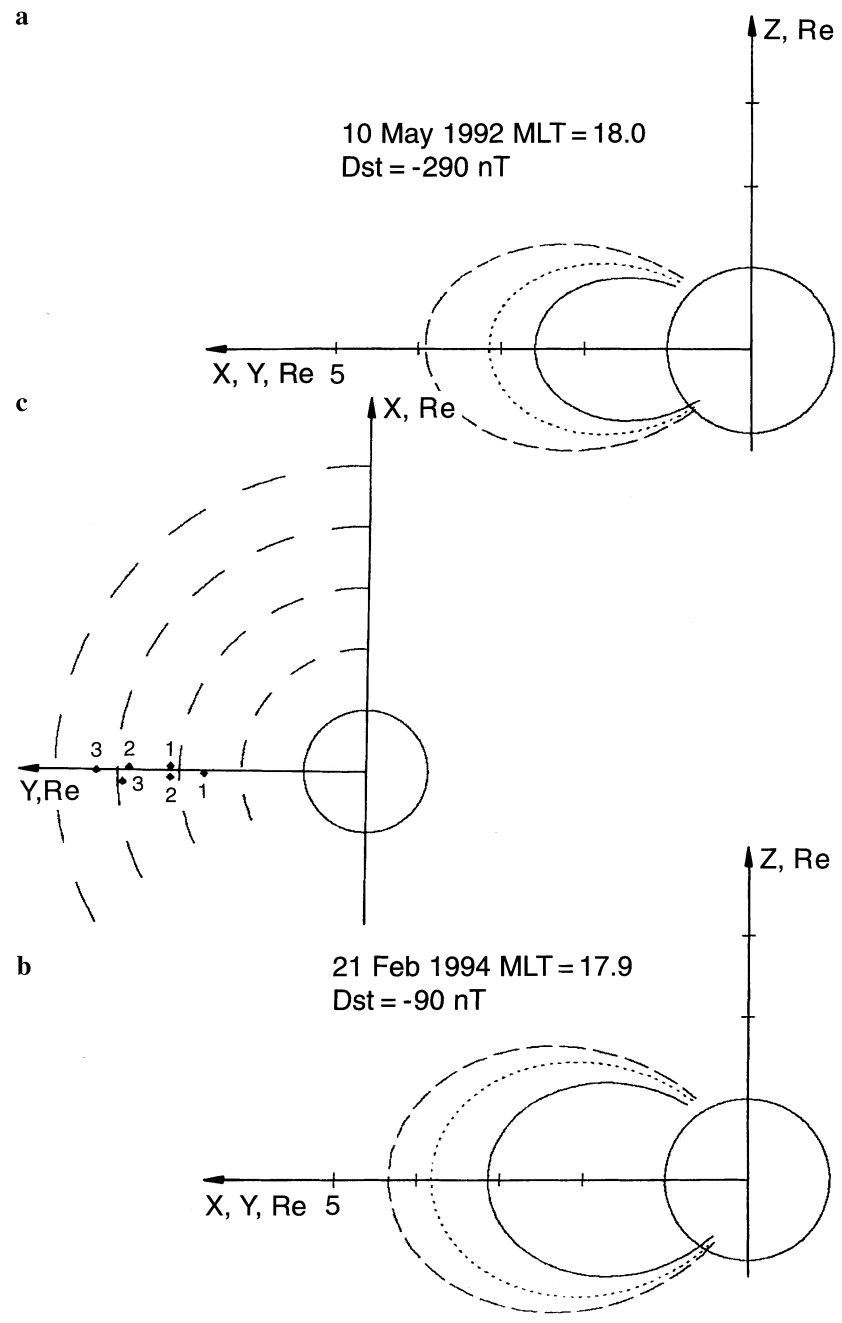

Fig. 8a-b. The mapping of the center and boundaries of eastward electrojets to the magnetospheric meridional (a and $\mathbf{b})$ and equatorial c (for both a, b events) cross sections using the paraboloid model of the magnetospheric magnetic field.

on Newell et al. (1996) identification data of DMSP F08 and DMSP F10 were used. Figures 8 and 9 show mapping results to the equatorial and meridional magnetospheric cross sections for the eastward and westward electrojets, correspondingly.

The eastward electrojet is mapped along quasidipole magnetic field lines to the inner magnetosphere in the evening sector. Its center and source region precipitating to the upper atmosphere ion energy flux maximum are located at geocentric distance $\sim 3.2 R_{e}$ for $D s t=-290 \mathrm{nT}$ and $\sim 3.8 R_{e}$ for $D s t=-90 \mathrm{nT}$. The interval between maximum and minimum geocentric distances of projections of poleward and equatorward boundaries of the eastward electrojet is $\sim 1.2 R_{e}$ independent of Dst intensity.

Geocentric distances $\sim(3-5.5) R_{e}$ are typical for the ring current position in the magnetosphere during magnetic storm intervals. Such spatial coincidence of the ring current and projection of the eastward electrojet to the magnetosphere gives additional evidence in favor
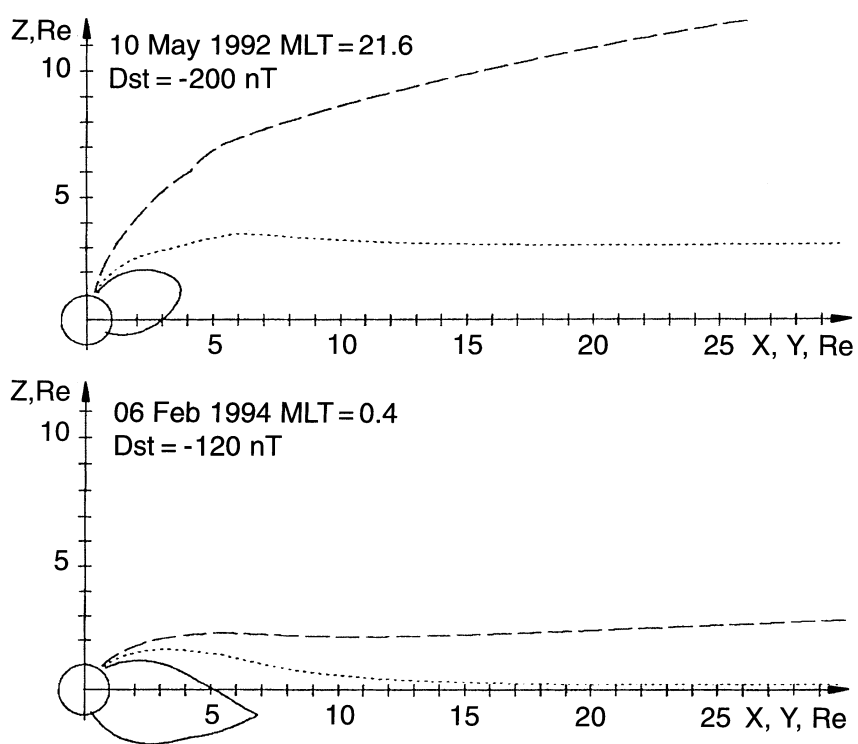

Fig. 9. Similar to Fig. 8 for westward electrojets:

of interrelationship between physical processes, leading to the eastward electrojet formation, and the ring current generation in the magnetospheric evening sector.

The westward electrojet (Fig. 9) is mapped to the nightside magnetosphere near midnight. For Dst $=-200 \mathrm{nT}$ the equatorward boundary is mapped to the magnetosphere along quasidipole magnetic field lines at $\sim 4 R_{e}$. The field lines threading the electrojet center and poleward boundary are elongated to the magnetospheric tail at distances $>50 R_{e}$. The magnetic field intensity at this distance on the field lines intersecting the electrojet center is $\sim 34 \mathrm{nT}$. The geomagnetic field intensity in the ring current region at the equator is $\sim 1100 \mathrm{nT}$.

At the $D s t=-120 \mathrm{nT}$ the westward electrojet equatorward boundary is elongated to the magnetospheric tail at the distance $\sim 7 R_{e}$ and the electrojet center and the poleward boundary are elongated to the distance more than $50 R_{e}$. The geomagnetic field intensity on the field lines intersecting the electrojet center and ring current center is $\sim 27 \mathrm{nT}$ and $\sim 800 \mathrm{nT}$, correspondingly.

In the latitudinal interval of the westward electrojet, where auroral discrete forms exist, the acceleration of electrons downward to the ionosphere and oxide ions upward to the magnetosphere to energy levels $\sim 10 \mathrm{keV}$ by the field-aligned electric field takes place. It means that during magnetic storm intervals the ring current a low energy ion component can be formed in the magnetosphere via the mechanism of direct acceleration of ionospheric ions within wide interval of $L$-shells, including small $L$ values. Accelerated to the magnetosphere ions with large $L$ values can participate in further earthward drift in the region of more intense magnetic fields. As a result of this drift, their energy increases due to adiabatic invariant conservation. It follows from model calculations that ion energy may increase $\sim 30$ times. Hence, such ions can be the main plasma population of the ring current. 
The paraboloid model allows us to separate influences of physically meaningful magnetospheric characteristics on the large-scale magnetospheric structure peculiarities. Table 1 contains geomagnetic latitudes of (1) the last (high-latitudinal) closed magnetic field line at noon, (2) the last quasidipolar field line at midnight (2), and the last field line, which is closed via (3) the magnetoshperic tail plasma sheet, when the input parameters of the paraboloid model vary.

Table 1 contains mapping results for February 21, 1995 event at $21.05 \mathrm{UT}$, when the dipole axis was tilted in the antisunward direction at $7.42^{\circ} . R_{1}, R_{2}, B_{R C}$ and $\Phi_{\infty}$ changed consequently from top to bottom. When $R_{1}$ changes, it was supposed that the value $R_{1}=6.5 R_{e}$ is characteristic the disturbed magnetosphere conditions, the value $R_{1}=7.5 R_{e}$ for the middle disturbed level and the value $R_{1}=9.0 R_{e}$ for the quiet magnetosphere conditions. The intensity of the magnetic field at the plasma sheet inner boundary $b_{t}$ was accepted as $-150 \mathrm{nT},-100 \mathrm{nT}$ and $-40 \mathrm{nT}$, correspondingly. Values of $\Phi_{\infty}$ for these three magnetosphere cases are shown in the upper part of Table 1.They were obtained using the relation between $\Phi_{\infty}, b_{t}, R_{1}$ and $R_{2}$ for the paraboloid model. Under changes of $R_{2}$ and $B_{R C}$ the intensity of magnetic field at the plasma sheet inner boundary is $b_{t}$ $=-200 \mathrm{nT} . \Phi_{\infty}$ variation in Table 1 lower part is selected in such a way, that $b_{t}$ equals consequently -200 $\mathrm{nT},-100 \mathrm{nT}$ and $-50 \mathrm{nT}$.

Results of calculations presented in Table 1 in the framework of the paraboloid model enable us to assume that:

1. The $R_{1}$ variation, when it increases from $6.5 R_{e}$ to 9.0 $R_{e}$, causes mainly a shift of the closed/open field lines boundary at midnight polewards by $9.7^{\circ}$. The dayside cusp and the nightside dipole line shifts by $1.9^{\circ}$ and $6.2^{\circ}$, correspondingly;

2. The $R_{2}$ variation, when it increases from $4.25 R_{e}$ to 6.0 $R_{e}$, gives rise, first of all, to the poleward shift of the night dipole line by $3.4^{\circ}$. The dayside cusp and closed/ open field lines boundary shift poleward by $0.5^{\circ}$ and equatorward by $2.7^{\circ}$, respectively;

3 . The $B_{R C}$ variation, when the ring current field intensity increases from $-40 \mathrm{nT}$ to $-150 \mathrm{nT}$, i.e., to that observed during moderate magnetic storm level, influence on the boundary location is weaker, than geocentric distances $R_{1}$ and $R_{2}$. At night the region of magnetic field lines with dipole character shifts equatorward by $1^{\circ}$ only and the dayside cups by $1.3^{\circ}$. The closed/open field lines boundary at the nightside magnetosphere shifts poleward by $2.2^{\circ}$.

4. The $\Phi_{\infty}$ variation, equivalent to the increase of magnetospheric tail currents magnetic field at the inner boundary from $-50 \mathrm{nT}$ to $-200 \mathrm{nT}$, leads to the most tangible shift of boundaries between regions with magnetic field lines of different character, especially at the night side.

Thus, the paraboloid model of magnetospheric magnetic field claims that influence of the ring current on the boundaries of structural regions in the magnetosphere is substantially weaker than the impact of magnetospheric tail current. The other result is a noticeable influence of geocentric distances $R_{1}$ and $R_{2}$ on location of boundaries.

\section{Conclusion}

1. Prominent equatorward shift of eastward electrojets during magnetic storms occurs. In the course of substorms the westward electrojet widens poleward covering auroral latitudes.

2. Comparison with auroral plasma precipitations has shown that the eastward electrojet pending magnetic storms is located predominantly at latitudes of diffuse precipitations equatorward of the discrete auroral forms region. This region is mapped along magnetic field lines to the inner magnetosphere at geocentric distance $2.5-4 R_{e}$, between the plasmapause and plasma sheet inner boundary in the magnetospheric tail. The eastward
Table 1. The paraboloid model calculation results with the different input parameters

\begin{tabular}{lllllll}
\hline$R_{1}, R_{e}$ & $R_{2}, R_{e}$ & $\Phi_{\infty}, \mathrm{Wb}$ & $B_{R C}, \mathrm{nT}$ & $\begin{array}{l}\text { Noon } \\
\text { closed }\end{array}$ & $\begin{array}{l}\text { Night } \\
\text { dipole }\end{array}$ & $\begin{array}{l}\text { Night } \\
\text { last closed }\end{array}$ \\
\hline $\begin{array}{l}\text { Different } R_{1} \\
6.5\end{array}$ & 4.25 & $0.0786 \mathrm{E}+10$ & -100 & $75.5^{\circ}$ & $60.8^{\circ}$ & $72.2^{\circ}$ \\
7.5 & 4.25 & $0.0524 \mathrm{E}+10$ & -100 & $76.2^{\circ}$ & $62.7^{\circ}$ & $75.9^{\circ}$ \\
9.0 & 4.25 & $0.0210 \mathrm{E}+10$ & -100 & $77.4^{\circ}$ & $67.0^{\circ}$ & $81.9^{\circ}$ \\
& Different $R_{2}$ & & & & & \\
7.5 & 4.25 & $0.1047 \mathrm{E}+10$ & -100 & $74.6^{\circ}$ & $58.7^{\circ}$ & $68.7^{\circ}$ \\
7.5 & 4.80 & $0.1083 \mathrm{E}+10$ & -100 & $74.8^{\circ}$ & $59.9^{\circ}$ & $67.6^{\circ}$ \\
7.5 & 6.00 & $0.1156 \mathrm{E}+10$ & -100 & $75.1^{\circ}$ & $62.1^{\circ}$ & $66.0^{\circ}$ \\
7.5 & & & Different $B_{R C}$ & & & \\
7.5 & 4.25 & $0.1047 \mathrm{E}+10$ & -40 & $75.3^{\circ}$ & $59.2^{\circ}$ & $67.2^{\circ}$ \\
7.5 & 4.25 & $0.1047 \mathrm{E}+10$ & -100 & $74.6^{\circ}$ & $58.7^{\circ}$ & $68.7^{\circ}$ \\
7.5 & 4.25 & $0.1047 \mathrm{E}+10$ & -150 & $74.0^{\circ}$ & $58.2^{\circ}$ & $69.4^{\circ}$ \\
7.5 & 4.25 & Different $\Phi_{\infty}$ & & & & \\
7.5 & 4.25 & $0.1047 \mathrm{E}+10$ & -100 & $74.6^{\circ}$ & $58.7^{\circ}$ & $68.7^{\circ}$ \\
\hline & 4.25 & $0.0524 \mathrm{E}+10$ & -100 & $76.2^{\circ}$ & $60.0^{\circ}$ & $75.9^{\circ}$ \\
\hline
\end{tabular}


electrojet center coincides with the region of maximum precipitating to the upper atmosphere ion energy flux.

3 . The westward electrojet is located in the latitudinal range of auroral plasma precipitations covering regions with both diffuse and discrete auroral forms. The electrojet center coincides with, or lies in the vicinity of, the electron acceleration events boundary (equatorial boundary of the auroral oval of the discrete auroral forms -b3a). During magnetic storms, in the substorm intervals, the westward electrojet is mapped to bigger part of the night magnetosphere, from its inner regions to the plasma sheet periphery.

4. Change of the ground magnetic field variations of the $R C$ current (from $-40 \mathrm{nT}$ to $-150 \mathrm{nT}$ ) and the magnetospheric tail currents (from $-50 \mathrm{nT}$ to $-200 \mathrm{nT}$ ) leads to an alteration of the magnetospheric magnetic field lines configuration. The ionospheric projection of the near noon magnetopause (boundary 1) and the tail current sheet inner boundary (boundary 2) shift equatorward. The volume of the inner magnetosphere with quasidipole field lines decreases. Influence of the tail currents on boundaries 1 and 2 positions is substantially more effective than the ring current impact. In the nightside magnetosphere these currents have an influence in opposite directions on the location of the boundary between closed (via the tail plasma sheet) and open field lines (boundary 3). A four fold increase of $R C$ and $T C$ magnetic fields leads to poleward shift of boundary 3 by $2.2^{\circ}$ ( $R C$ impact) and to equatorward shift by $13.4^{\circ}$ (TC influence via the magnetic flux $\Phi_{\infty}$ increase).

5. Variations of the solar wind, electric fields in the magnetospheric tail and plasma injections from the tail to the inner magnetosphere affect geocentic distances to the subsolar magnetopause point $R_{1}$ and the magnetospheric tail current sheet inner boundary $R_{2}$. Increase of $R_{1}$ leads to the poleward shift of all three characteristic magnetospheric boundaries. Moreover, the interval of the dayside cusp boundary shift is three times less, than similar shift of the inner magnetosphere boundary in the night sector. Increase of $R_{2}$ leads to the poleward shift of both the dayside cusp boundary and the night inner magnetosphere boundary. This shift at night is substantially more prominent, than in day time.

Acknowledgements. We appreciate very much the fruitful discussions with H.Luehr. We are grateful to the EISCAT and IMAGE magnetometer chain teams. The IMAGE magnetometer data used in this article were collected as part of the German-FinnishNorwegian-Polish project conducted by the Technical University of Braunschweig. This work has been supported by RFBR grants 96-05-66279 and 95-05-14057, INTAS-RFBR-95-0932.

Topical Editor K. -H. Glassmeier thanks T. J. Rosenberg for his help in evaluating this paper.

\section{References}

Akasofu, S.-I., in Polar and magnetospheric substorms, D. Reidel Dordrecht-Holland, 1968.

Akasofu, S.-I., and S. Chapman, Solar-Terrestrial Physics, Clarendon Press, Oxford, 1972.

Alexeev, I. I., E. S. Belenkaya, V. V. Kalegaev, Y. I. Feldstein and A. Grafe, Magnetic storms and magnetotail currents, $J$. Geophys. Res., 101, 7737-7747, 1996.
Dronov, A. V., T. I. Morozova, E. H. Sosnovetz, L. V. Tverskaya, V. I. Tulupov, and $\mathbf{O}$. V. Khorosheva, Relationship between the ring current, electron precipitation regions and auroral luminosity in the dusk-midnight sector of the magnetosphere, Geomagn. Aeron., 28, 1011-1013, 1988.

Feldstein, Y. I., and Y. I. Galperin, The auroral luminosity structure in the high-latitude upper atmosphere: its dynamics and relationship to the large-scale structure of the Earth's magnetosphere, Rev. Geophys. Space Phys., 23, N 3, 217-275, 1985.

Feldstein, Y. I. and Y. I. Galperin, The auroral precipitations structure in the magnetosphere night sector, Cosmic Res., 34, N 3, 227-247, 1996.

Feldstein, Y. I., A. Grafe, L. I. Gromova and V. A. Popov, Auroral electrojets during geomagnetic storms, J. Geophys. Res., 102, 14223-14235, 1997.

Feldstein, Y. I., A. E. Levitin, S. A. Golyshev, L. A. Dremuhina, U. B. Vestchezerova, T. E. Valchuk and A. Grafe, Ring current and auroral electrojets in connection with interplanetary medium parameters during magnetic storms, Ann. Geophysicae, 12, 602611, 1994.

Galperin, Y. I. and Y. I. Feldstein, Auroral luminosity and its relationship to magnetospheric plasma domains, in Auroral Physics, Cambridge UP, eds. Meng C.-I., M. J. Rycroft, and L. A. Frank, 207-222, 1991.

Galperin, Y. I. and Y. I. Feldstein, Mapping of the precipitation region to the plasma sheet, J. Geomag. Geoelectr., 48, N5-6, 857-875, 1996.

Grafe, A., R. J. Pellinen, W. Baumjohann and M. Vallinkoski, Development of the auroral electrojets on 16 March 1978: an event study, Geophysica, 83, 113-141, 1987.

Kamide, Y. and S.-I. Akasofu, Latitudinal cross section of the auroral electrojet and its relation to the interplanetary magnetic field polarity, J. Geophys. Res., 79, 3755-3771, 1974.

Khorosheva, O. V., Relation of the magnetospheric disturbances to the parameters of the interplanetary medium, Geomagn. Aeron., 26, 447-453, 1986.

Khorosheva, O. V., Magnetospheric disturbances and the associated dynamics of ionospheric electrojets, aurorae and plasmapause, Geomagn. Aeron., 27, 804-811, 1987.

Kuznetsov, S.N, A model of ring current based on the DesslerParker-Sckopke theorem, Radiation Measurements, 26, N3, 403-404, 1996.

Luehr, H., S. Thurey and N. Klocker, The EISCAT-magnetometer cross, operational aspects-first results, Geophys. Surv., 6, 305$315,1984$.

Newell, P. T., Y. I. Feldstein, Y. I. Galperin and C.-I. Meng, The morphology of nightside precipitation, J. Geophys. Res., 101, N5, 10737-10748, 1996.

Rostoker, G., E. Friedrich, and M. Dobs, Physics of magnetic storms in Geophysical Monograph, eds B.T. Tsurutani, W.D., Gonzalez, Y. Kamide, J.K. Arballo, AGU, N 98. 149-160

Sanchez, E. R., B. H. Mauk, P. T. Newell and C.-I. Meng, Low-altitude observations of the evolution of substorm injection boundaries, J. Geophys. Res., 98, N4, 5815-5838, 1993.

Swider, W., Precipitating and trapped ions and electrons observed at $840 \mathrm{~km}$ during the great magnetic storm of February 1986, $J$. Geophys. Res., 95, 10417-10425, 1990.

Troshichev, O. A., N. P. Dmitrieva, and B. M. Kuznetsov, Polar cap magnetic activity as a signature of substorm development, Planet. Space Sci., 27, 217-221, 1979.

Tsyganenko, N. A., Global quantitative models of the geomagnetic field in the cislunar magnetosphere for different disturbance levels, Planet. Space Sci., 35, 1347-1358, 1987.

Tsyganenko, N. A., A magnetospheric magnetic field model with a warped tail current sheet, Planet. Space Sci., 37, 5-20, 1989.

Vennerstrom, S., E. Friis-Christensen, O. A. Troshichev, and V. G. Andersen, Comparison between the polar cap index, PC, and the auroral electrojet indices AE, AL and AU, J. Geophys. Res., 96, $101-113,1991$. 
Viljanen, A. and L. Hakkinen, IMAGE magnetometer network, Proc of the 2nd International Workshop for the co-ordination of ground-based observations and Claster, 1996
Weimer, D. R., L. A. Reinleitner, J. R. Kan, L. Zhu and S.-I. Akasofu, Saturation of the auroral electrojet current and the polar cap potential, J. Geophys. Res., 95, 18981-18988, 1990. 